POS PROCEEDINGS

\title{
Fermilab Neutron Therapy Facility Neutron Spectrum Determination by Threshold Foils
}

\author{
Zhonglu Wang, Nolan E. Hertel, and Eric Burgett ${ }^{*}$ \\ Georgia Institute of Technology \\ 900 Atlantic Drive, Atlanta, GA, 30318, USA \\ gte771y@prism.gatech.edu \\ nolan.hertel@me.gatech.edu \\ eric.burgett@nnrc.gatech.edu
}

Arlene Lennox

Fermi National Accelerator Laboratory

FermilabMail Stop301, Kirk and Wilson Streets, Batavia, IL 60510, USA

alennox@fnal.gov

The Fermilab Neutron Therapy Facility produces neutrons by bombarding a 2.21 -cm-thick beryllium target with $66-\mathrm{MeV}$ protons. The neutron beam is collimated to produce a desired field size and is monitored using dual parallel-plate ionization chambers. The neutron spectrum of this beam was determined by unfolding bare and moderated foil activation data and an MCNPX calculation of the spectrum was also performed.

Aluminium and copper activation foils were selected for the neutron fluence measurement. The activation products in the foils were measured for various levels of moderation using polymethylmethachrylate (PMMA) slabs. Five reactions were considered in the experiment: ${ }^{27} \mathrm{Al}(\mathrm{n}, \gamma){ }^{28} \mathrm{Al},{ }^{27} \mathrm{Al}(\mathrm{n}, \mathrm{p}){ }^{27} \mathrm{Mg},{ }^{27} \mathrm{Al}(\mathrm{n}, \alpha){ }^{24} \mathrm{Na},{ }^{65} \mathrm{Cu}(\mathrm{n}, \gamma){ }^{66} \mathrm{Cu}$ and ${ }^{63} \mathrm{Cu}(\mathrm{n}, 2 \mathrm{n}){ }^{62} \mathrm{Cu}$. The activities of these end products after the irradiation period were used to compute their production rates during irradiation.

Responses as a function of neutron energy were generated for the production of ${ }^{28} \mathrm{Al},{ }^{27} \mathrm{Mg}$, ${ }^{24} \mathrm{Na},{ }^{66} \mathrm{Cu}$ and ${ }^{62} \mathrm{Cu}$ using MCNPX and the LA150N library. The resulting response matrix was binned into 49 energy groups from $10^{-10} \mathrm{MeV}$ to $70 \mathrm{MeV}$ and includes responses both for bare foils and moderated foils. The PTB code MXD_FC33 code was used to unfold the activation data. The resulting spectrum is compared to both the MCNPX-computed spectrum as well as a previous measurement by Cupps and Elwyn

International Workshop on Fast Neutron Detectors

University of Cape Town, South Africa

April 3-6, 2006

\footnotetext{
${ }^{*}$ Speaker 


\section{Introduction}

The Fermilab Neutron Therapy Facility (NTF) produces neutrons by bombarding a 2.21$\mathrm{cm}$-thick beryllium target with $66-\mathrm{MeV}$ protons. The protons lose $49 \mathrm{MeV}$ in the beryllium target and are stopped by a $0.5-\mathrm{mm}$ gold backing [1]. A set of collimators are used to produce different field sizes. The neutron flux is monitored by dual parallel-plate ionization chambers during experiments and therapy. The ionization chambers are calibrated so that one monitor unit (MU) produces a dose of one gray at $10-\mathrm{cm}$ deep in tissue for a $10 \times 10 \mathrm{~cm}^{2}$ standard treatment field.

Cupps et al.[2] measured the spectral neutron fluence rate of the Fermilab NTF using gold and indium foil activation in 1996. Ross et al.[3] calculated the neutron spectrum using the LAHET and HMCNP codes in 1997. The shapes of the calculated and measured neutron spectrum from those works were in reasonably agreement. Ross et al. also calculated the neutron spectrum of the neutron therapy facility at the National Accelerator Center (NAC) in South Africa and this calculation agreed well with the time-of-flight measurements of that beam by Jones et al.[4] So the shape of the Fermilab NTF neutron spectra measured by Cupps et al. and calculated by Ross et al. should be reasonably reliable.

Sweezy [5] modeled the Fermilab NTF neutron beam using MCNPX and the LA-150 neutron cross-section library.[6] He tracked $6.0 \times 10^{9}$ source protons which yielded $9.0 \times 10^{6}$ neutrons incident on the face of the collimator. This neutron source was written to a surface source file for subsequent neutron transport calculations in Sweezy's work. Comparison of Sweezy's depth-dose measurements and calculations indicated that MCNPX underestimated the fast neutron and gamma dose by about a factor of 3.[5] The current measurement of the neutron spectrum was undertaken to ensure validate a neutron source term for use in future depth-dose modeling efforts to support of the design of a neutron capture augmented fast neutron therapy beam.

\section{Methods}

\subsection{Activation Foils and Activation Products}

Aluminum and copper foils were chosen to be the activation detectors because they have evaluated neutron cross section data up to $150 \mathrm{MeV}$ in the MCNPX library and their activation products have appropriate half-lives and gamma ray emissions for counting. Polymethylmethachrylate (PMMA) slabs of various thicknesses were placed in front of the copper and aluminum foils to provide additional energy information. The foils were attached to the center of the downstream wall of a moderator box which has dimensions of $30 \mathrm{~cm} \mathrm{x} 30 \mathrm{~cm} \mathrm{x}$ $15 \mathrm{~cm}$. The thickness of the box walls is $0.6 \mathrm{~cm}$. Up to 12 PMMA slabs of various thicknesses can be inserted into the box, allowing moderator thicknesses to be varied from $1.2 \mathrm{~cm}$ (empty) to $14.5 \mathrm{~cm}$ (all slabs inserted). 
Five reactions are considered for the experiment: ${ }^{27} \mathrm{Al}(\mathrm{n}, \gamma){ }^{28} \mathrm{Al},{ }^{27} \mathrm{Al}(\mathrm{n}, \mathrm{p}){ }^{27} \mathrm{Mg},{ }^{27} \mathrm{Al}$ $(\mathrm{n}, \alpha){ }^{24} \mathrm{Na},{ }^{65} \mathrm{Cu}(\mathrm{n}, \gamma){ }^{66} \mathrm{Cu}$ and ${ }^{63} \mathrm{Cu}(\mathrm{n}, 2 \mathrm{n}){ }^{62} \mathrm{Cu}$. The decay data (half-life, gamma-ray energy and emission probability) of these activation products are shown in Table 1.

Table 1. Decay data of the Activation Products [7,8]

\begin{tabular}{|c|c|c|c|c|}
\hline Reactions & Radionuclide & $\mathrm{T}_{1 / 2}$ & $\mathrm{E}_{\gamma}(\mathrm{keV})$ & $\mathrm{P}_{\gamma}(\%)$ \\
\hline${ }^{27} \mathrm{Al}(\mathrm{n}, \gamma){ }^{28} \mathrm{Al}$ & ${ }^{28} \mathrm{Al}$ & $2.2414 \mathrm{~min}$ & 1778.9 & 100 \\
\hline${ }^{27} \mathrm{Al}(\mathrm{n}, \mathrm{p}){ }^{27} \mathrm{Mg}$ & ${ }^{27} \mathrm{Mg}$ & \multirow{2}{*}{$9.458 \mathrm{~min}$} & 843.76 & 71.0 \\
\cline { 4 - 5 } & & & 1014.4 & 28.0 \\
\hline${ }^{27} \mathrm{Al}(\mathrm{n}, \alpha){ }^{24} \mathrm{Na}$ & ${ }^{24} \mathrm{Na}$ & \multirow{2}{*}{$14.9512 \mathrm{~h}$} & 1368.5 & 100 \\
\cline { 4 - 5 } & & $9.67 \min$ & 8754.1 & 99.9 \\
\hline${ }^{65} \mathrm{Cu}(\mathrm{n}, \gamma){ }^{66} \mathrm{Cu}$ & ${ }^{66} \mathrm{Cu}$ & $5.12 \min$ & 1039.2 & 0.15 \\
\hline${ }^{63} \mathrm{Cu}(\mathrm{n}, 2 \mathrm{n}){ }^{62} \mathrm{Cu}$ & ${ }^{62} \mathrm{Cu}$ & \multicolumn{2}{c}{} \\
\hline
\end{tabular}

Each irradiated foil was counted using an HPGe gamma-ray spectrometer to determine the ${ }^{28} \mathrm{Al},{ }^{27} \mathrm{Mg},{ }^{24} \mathrm{Na},{ }^{66} \mathrm{Cu}$ and ${ }^{62} \mathrm{Cu}$ activities at the end of each irradiation. The proton current was monitored during the irradiation and its observed fluctuation was at most $2 \%$. So the neutron beam intensity was assumed to be constant during the irradiation and therefore, the production rates of the activation products are also assumed to be constant. The production rates were obtained by

$$
\dot{P}_{j}=\frac{A_{j}(0) \lambda_{j}}{1-e^{-\lambda_{j} T}} \frac{1}{m_{j}}
$$

where $\dot{P}_{j}$ is the production rate of radionuclide $j(\mathrm{~Bq} / \mathrm{s} / \mathrm{g}), \lambda_{j}$ is the decay constant of radionuclide $j, T$ is the irradiation time, $m_{j}$ is the mass of the foil in which radionuclide $j$ was produced and $A_{j}(0)$ is the activity of radionuclide $j$ at the end of irradiation. The activity of radionuclide $j$ at the end of the irradiation is calculated by

$$
A_{j}(0)=\frac{C_{i j}}{P_{i j} \varepsilon_{i}} \frac{\lambda_{j}}{1-e^{-\lambda_{j} T_{R}}} \frac{T_{R}}{T_{L}} \cdot e^{\lambda_{j} T_{D}}
$$

where $C_{i j}$ is the net peak counts of energy $E_{i}$ of radionuclide $j, P_{i j}$ is its gamma-ray emission probability, $\varepsilon_{i}$ is the detection efficiency, $T_{R}$ is the real counting time, $T_{L}$ is the live counting time and $T_{D}$ is the decay time (from the end of irradiation to the start of the counting).

\subsection{HPGe Detector Calibration}

The HPGe detector is calibrated using a NIST-traceable mixed gamma-ray point source. The activation foils must be counted on the surface of the detector after irradiation in the beam because of their low activities. So the gamma-ray efficiencies for this geometry must be determined. Due to the cascading emission of two the two gamma rays from ${ }^{60} \mathrm{Co}$ and ${ }^{88} \mathrm{Y}$, 
summing effects were unavoidable in the counting of the calibration standard. The high energy portion (above $889 \mathrm{keV}$ ) of the efficiency function for the small source-to-detector distance geometry needs to be corrected for the summing effect. The MCNP code was used in the calculation to perform this correction[9]. The conversion factors for a point source to a disc source and the correction coefficients of self-absorption of the foils were measured and taken into account in the efficiency curves. The uncertainty in the detector efficiency is approximately $3.4 \%$.

\subsection{Neutron Spectrum Unfolding}

The foil activation data were unfolded to obtain a neutron spectrum using the MXD_FC33 code[10]. In principle, the solution of equation (3) is the energy-dependent neutron fluence rate.

$$
\begin{gathered}
\dot{P}_{j}(k)+\varepsilon_{j}(k)=\sum_{l=1}^{n} \phi_{l} R_{l j}(k) \\
\sum_{k} \sum_{j} \frac{\varepsilon_{j}(k)^{2}}{\sigma_{j}(k)^{2}}=\Omega
\end{gathered}
$$

In these equations, $\dot{P}_{j}(k)$ is the production rate of the radionuclide $j$ for moderator thickness $\mathrm{k}$ in unit of $\mathrm{Bq} / \mathrm{s} / \mathrm{g}, \phi_{l}$ is the neutron fluence rate of energy group $l$ in unit of $1 / \mathrm{cm}^{2} / \mathrm{s}, R_{l j}(k)$ is the response matrix for production of the activation product $j$ for moderator thickness $k$ over energy group $l\left(\mathrm{~Bq} / \mathrm{g}\right.$ per $\left.\mathrm{n} / \mathrm{cm}^{2}\right)$ and $\Omega$ is a parameter set by the user (typically, $\Omega$ is set to the number of detectors).

There are fewer equations than unknowns in equation (3) and no unique solution can be obtained. Therefore, an initial spectrum is provided to the MXD_FC33 code to start the unfolding process. The MCNPX-calculated neutron spectrum was used as the initial spectrum to constrain the unfolding.

\subsection{Calculation of the Response Matrices}

The responses for the production of ${ }^{28} \mathrm{Al},{ }^{27} \mathrm{Mg},{ }^{24} \mathrm{Na},{ }^{66} \mathrm{Cu}$ and ${ }^{62} \mathrm{Cu}$ in the foils were calculated using MCNPX with the library LA150N. The energy scale range was divided into 49 groups from $10^{-10} \mathrm{MeV}$ to $70 \mathrm{MeV}$. The response functions for ${ }^{28} \mathrm{Al},{ }^{27} \mathrm{Mg},{ }^{24} \mathrm{Na},{ }^{66} \mathrm{Cu}$ and ${ }^{62} \mathrm{Cu}$ are shown Figures 1 to 5, respectively. Only the responses for six moderator thicknesses are shown.

The MCNPX input files modeled the experimental setup as exactly as possible. A $10 \mathrm{~cm} \mathrm{x}$ $10 \mathrm{~cm}$ parallel neutron beam was directed perpendicularly on the front face of the PMMA box with the copper and aluminum foils mounted on the back face. The density of the PMMA, $\left(\mathrm{C}_{5} \mathrm{H}_{8} \mathrm{O}_{2}\right)_{\mathrm{n}}$, is $1.19 \mathrm{~g} / \mathrm{cm}^{3}$. The tally multiplication cards (FM) and special treatment card (SCX) 
were used to tally the responses of neutrons for different incident energy bins in one MCNPX run.

\section{Experiments}

Pure (99.99\%) aluminum foils of diameter $1.693 \mathrm{~cm}$ and $0.1 \mathrm{~cm}$ thickness and pure copper foils of the same diameter and $0.05 \mathrm{~cm}$ thickness were placed at the center on the downstream face of the moderator. The copper foil was placed in front of the aluminum foil. The front face of the moderator was at the treatment beam isocenter (190 cm from the beryllium target). The setup is the same as described in the MCNPX simulations. For each irradiation, $1 \mathrm{MU}$ or $2 \mathrm{MU}$ of beam was delivered, resulting in irradiation times of 3.4 or 6.8 minutes.

The foils were taken immediately after irradiation to an HPGe detector for counting. The aluminum foil was counted first for less than $5 \mathrm{~min}$ to determine the activity of short-lived ${ }^{28} \mathrm{Al}$ and then the copper foil was counted for 5 to 10 mins. A relatively long counting of the aluminum foil was performed to determine the ${ }^{27} \mathrm{Mg}$ and ${ }^{24} \mathrm{Na}$ activities.

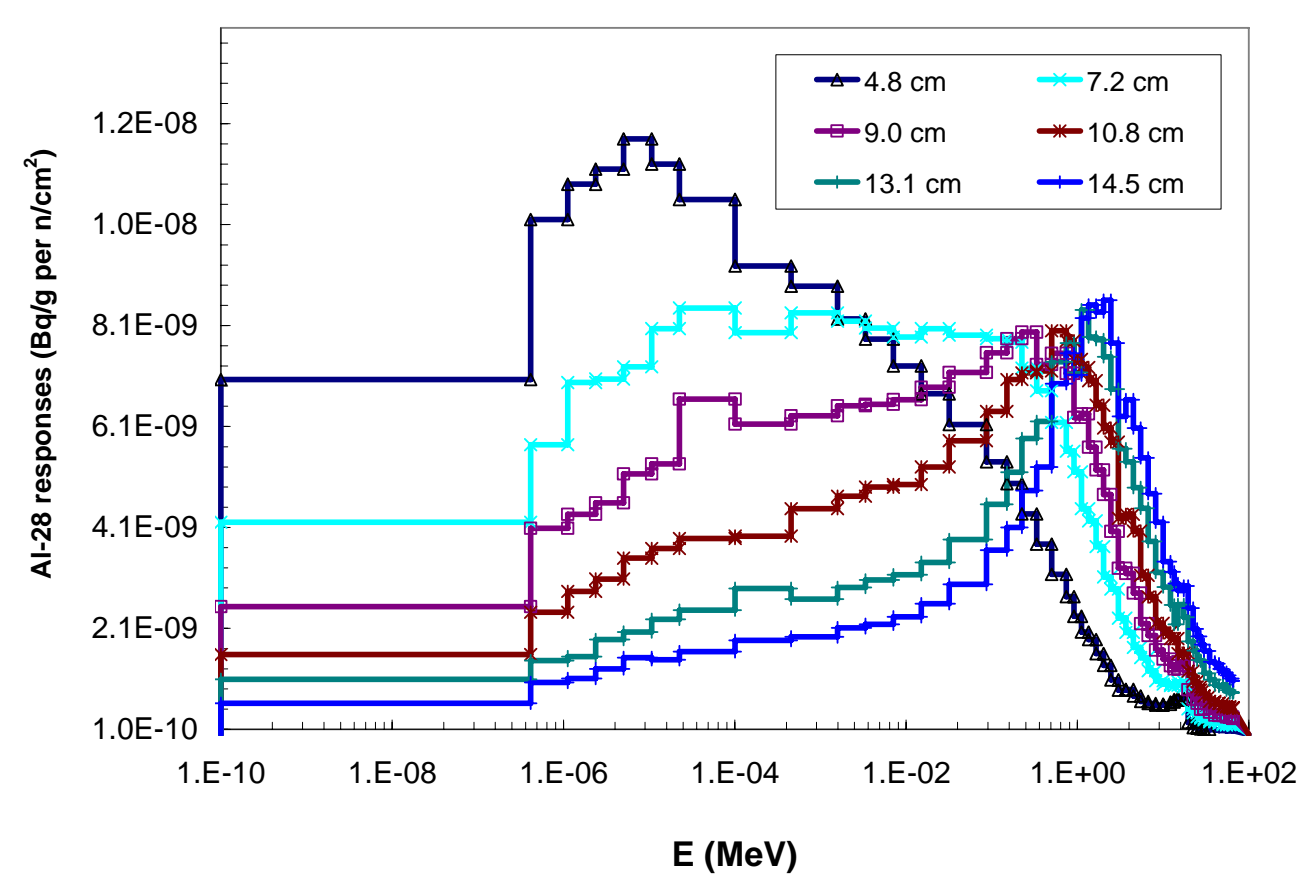

Fig. $1 .{ }^{27} \mathrm{Al}(\mathrm{n}, \gamma)^{28} \mathrm{Al}$ Response Functions Behind Various Moderator Thicknesses. 


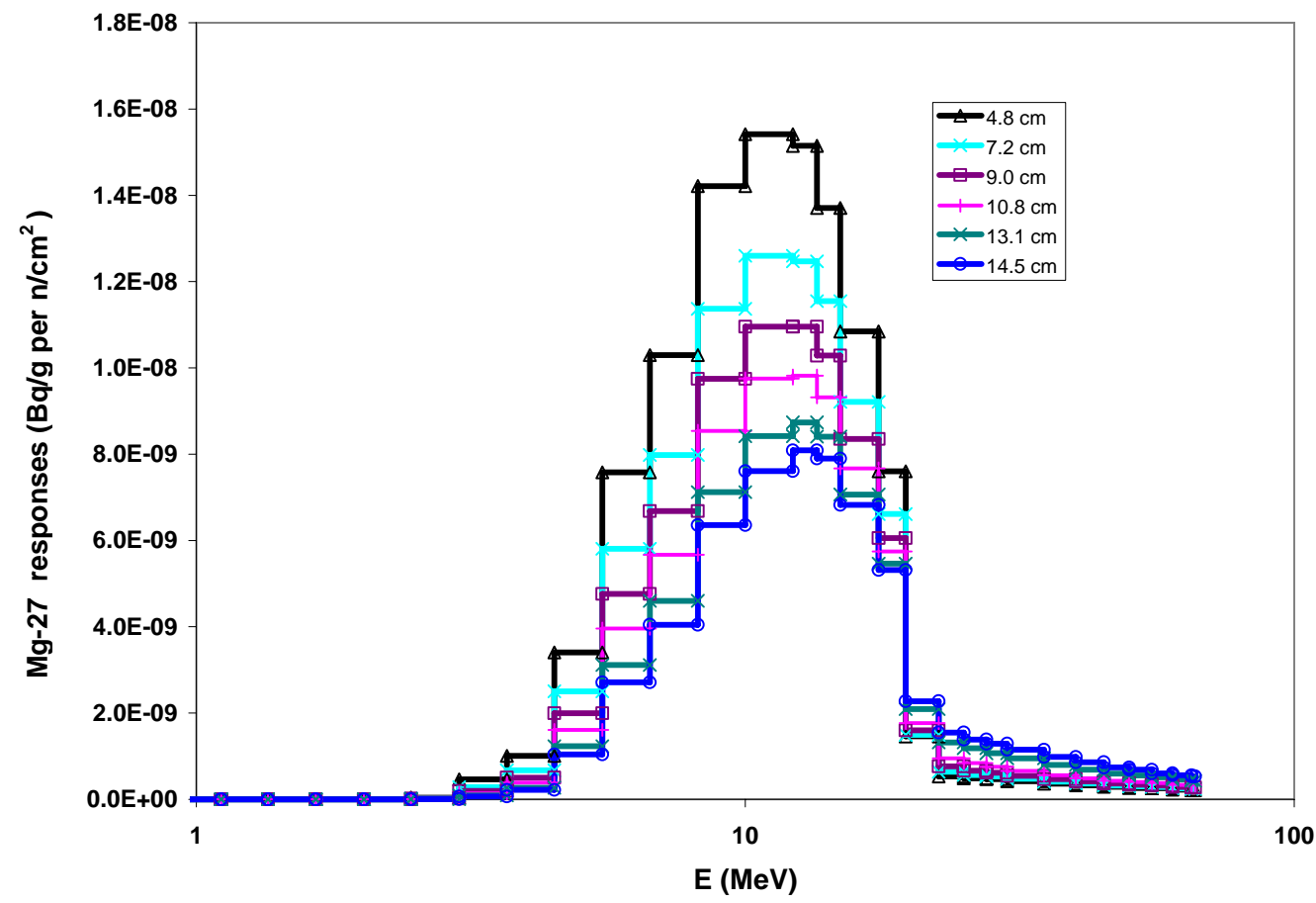

Fig. $2 .{ }^{27} \mathrm{Al}(\mathrm{n}, \mathrm{p}){ }^{27} \mathrm{Mg}$ Response Functions Behind Various Moderator Thicknesses.

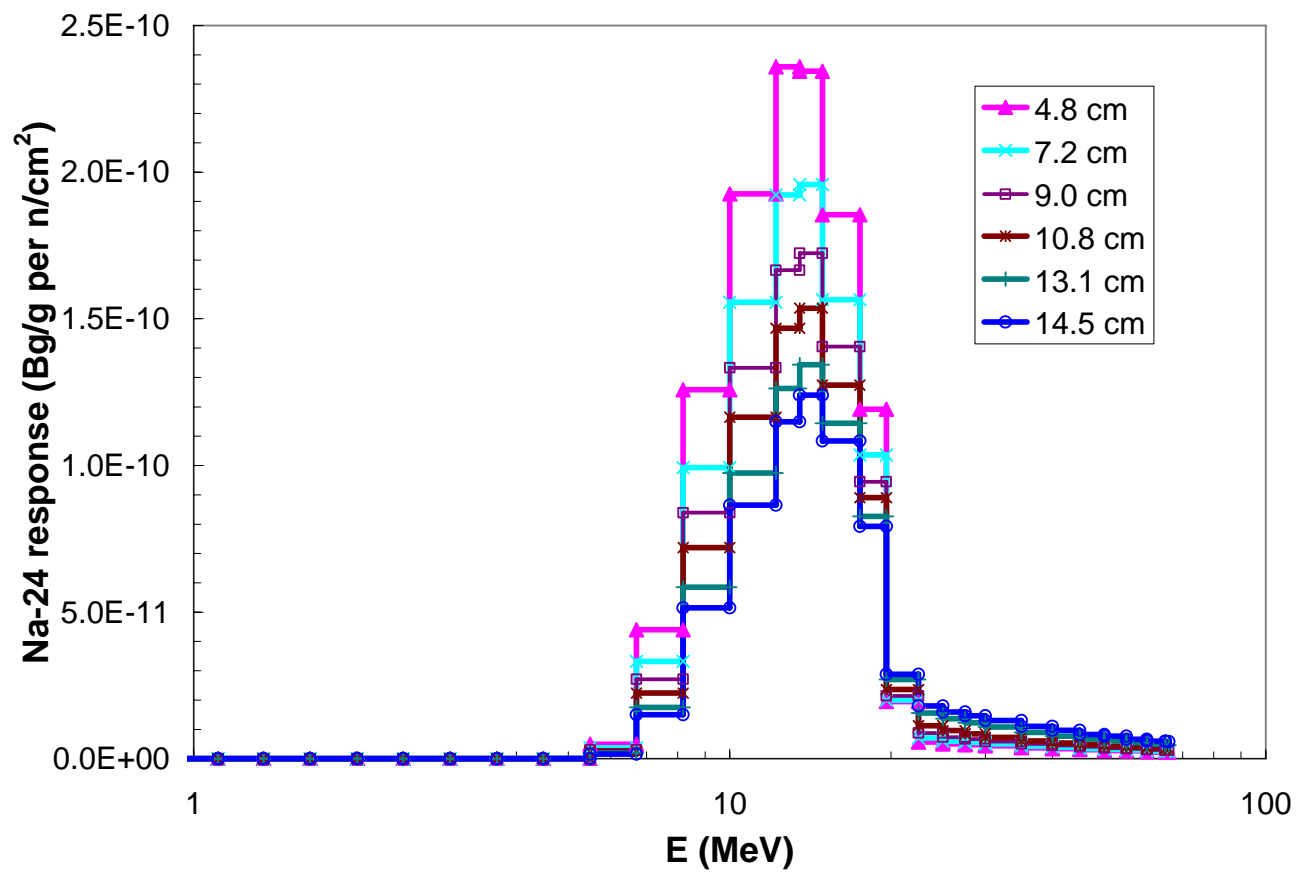

Fig. $3 .{ }^{27} \mathrm{Al}(\mathrm{n}, \alpha)^{24} \mathrm{Na}$ Response Functions Behind Various Moderator Thicknesses. 


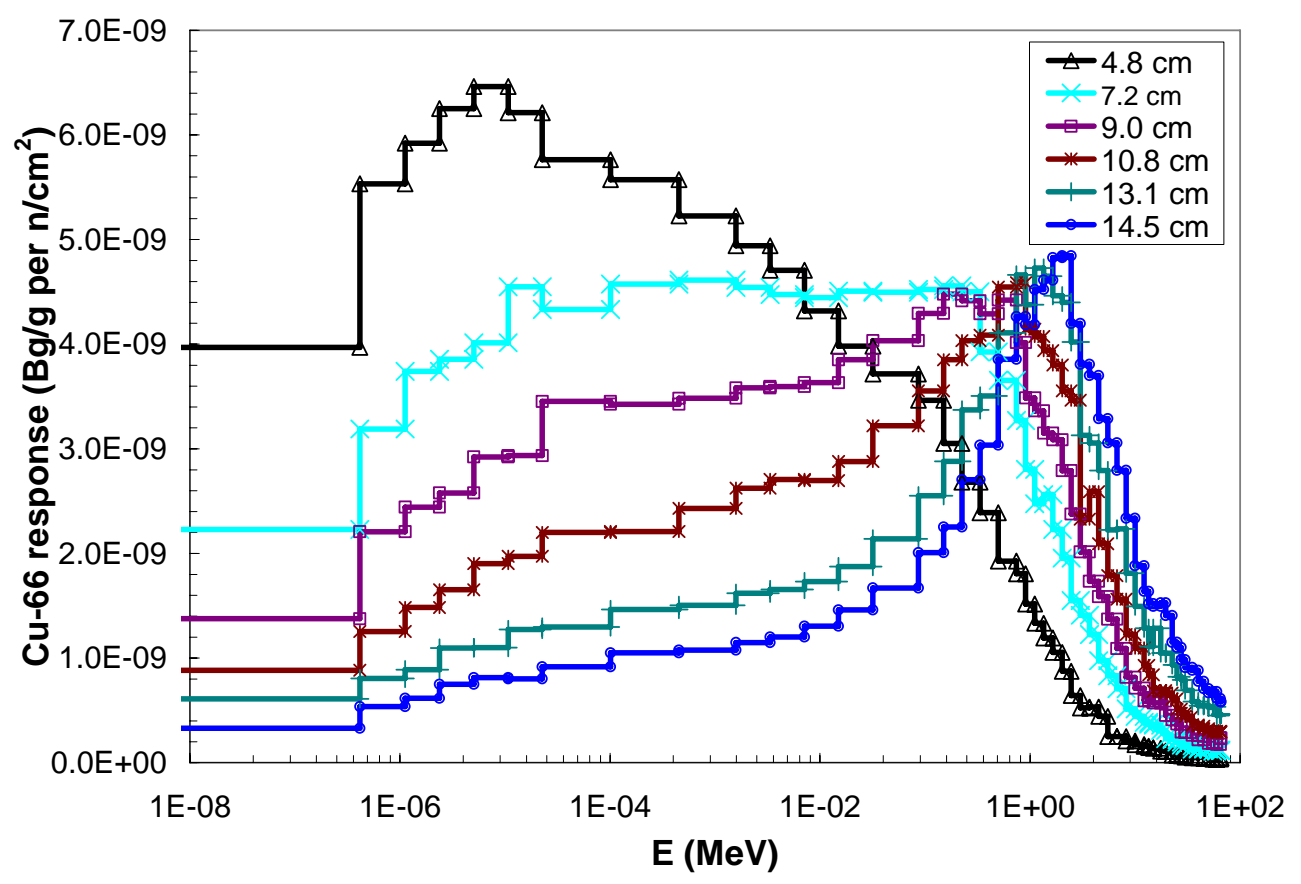

Fig. $4 .{ }^{65} \mathrm{Cu}(\mathrm{n}, \gamma){ }^{66} \mathrm{Cu}$ Response Functions Behind Various Moderator Thicknesses.

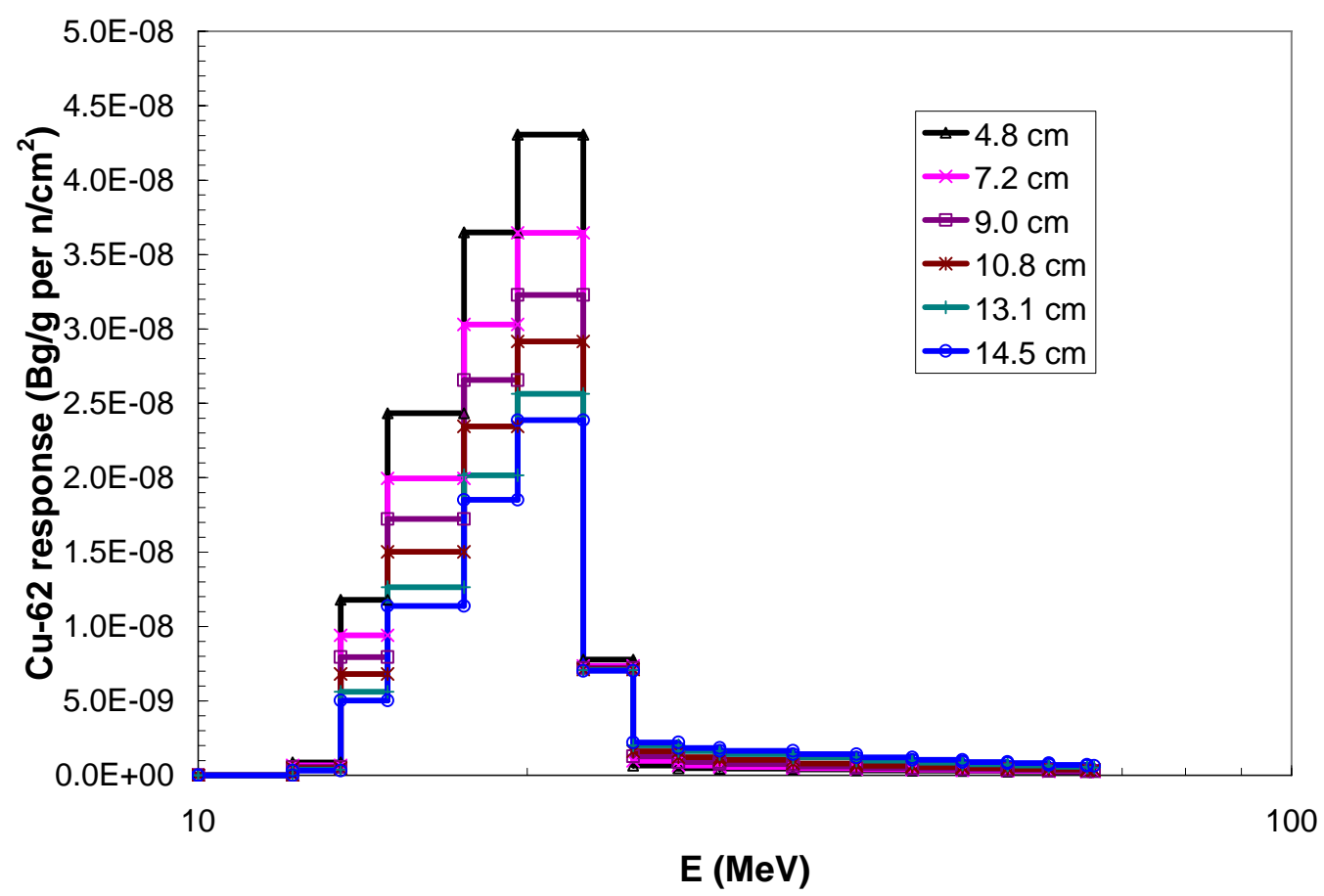

Fig. 5. ${ }^{63} \mathrm{Cu}(\mathrm{n}, 2 \mathrm{n}){ }^{62} \mathrm{Cu}$ Response Functions Behind Various Moderator Thicknesses. 


\section{Results}

The activity production rates for foils behind various moderation thicknesses are shown in Table 2. Because of the short irradiation time, saturated activities of the activation products were not attained. So the activity production rates were calculated using equations (1) and (2).

The shape of the unfolded neutron spectrum is affected by the starting spectrum. Two starting spectra, the MCNPX-calculated NTF neutron spectrum and the spectrum measured by Cupps et al. were used as the starting spectra for unfolding. The unfolded spectra and the MCNPX spectrum are shown in Fig. 6. A comparison between this work and Cupps et al. is shown in Fig. 7.

The resulting unfolded total neutron fluence rate at $190 \mathrm{~cm}$ isocenter for a $10 \times 10 \mathrm{~cm}^{2}$ field was $1.22 \times 10^{8} \mathrm{n} / \mathrm{cm}^{2}$-s for a beam current of $1.5 \times 10^{14} \mathrm{proton} / \mathrm{s}$ in this work. When scaled by the proton beam current, the fluence rate in this work agrees well with the value reported by Cupps et al.[2], which was $1.35 \times 10^{8} \mathrm{n} / \mathrm{cm}^{2}$-s for a beam current of $1.7 \times 10^{14}$ proton/s.

An MCNPX calculation which tracked $10^{9}$ protons resulted in a fluence of $6.32 \times 10^{-7}$ neutrons $/ \mathrm{cm}^{2}$ per proton at the $190 \mathrm{~cm}$ isocenter. So a total neutron fluence rate of $9.48 \times 10^{7}$ $\mathrm{n} / \mathrm{cm}^{2}-\mathrm{s}$ is obtained for a beam of $1.5 \times 10^{14}$ proton/s. The ratio of the measured to the calculated total fluence rate in the present work is 1.29. During the course of this work, it was discovered that the MCNPX input file of Sweezy [5] used an isotropic proton disc source instead of a parallel beam, causing half of the protons to miss the Be target. Therefore, the previously observed factor of three between the calculated and measured depth-dose distributions is mostly attributed to a modeling error.

Table 2. Production Rates (Bq/g/sec) Of The Radioisotopes For Foils Behind Different Moderation Thickness

\begin{tabular}{ccccccc}
\hline $\begin{array}{c}\text { Moderation } \\
\text { thickness }\end{array}$ & $4.8 \mathrm{~cm}$ & $7.2 \mathrm{~cm}$ & $9 \mathrm{~cm}$ & $10.8 \mathrm{~cm}$ & $13.1 \mathrm{~cm}$ & $14.5 \mathrm{~cm}$ \\
\hline${ }^{28} \mathrm{Al}$ & 12.51 & 19.91 & 26.30 & 32.11 & 37.33 & 41.45 \\
${ }^{27} \mathrm{Mg}$ & 30.69 & 25.75 & 24.01 & 22.36 & 22.14 & 21.13 \\
${ }^{24} \mathrm{Na}$ & 0.34 & 0.30 & 0.28 & 0.28 & 0.26 & 0.24 \\
${ }^{62} \mathrm{Cu}$ & -- & 64.41 & 45.00 & 38.56 & 46.73 & 39.83 \\
${ }^{66} \mathrm{Cu}$ & 7.83 & 10.53 & 13.48 & 19.12 & 23.20 & 26.54
\end{tabular}

\section{Discussion}

Uncertainties in the measurement of the activities of the activation products ranged from 1 to $20 \%$ due to counting statistics coupled with the uncertainty of the detector efficiency $(3.4 \%)$. The production rates also suffer from the $2 \%$ fluctuation of the proton current and the uncertainty in the determination of the proton current. All in all the uncertainty in the unfolded neutron fluence rate is approximately $15 \%$.

The advantages of selecting aluminum and copper foils as the activation detectors are that the short half-lives of the activation products require short irradiation times and that the 
resulting radionuclides have appropriate gamma-ray energies for counting coupled with reasonable emission probabilities. These properties make it easy to determine their activities.

From the response functions shown in Fig. 1 to 5, one can see that different moderating thicknesses for the threshold activation foils do not lead to distinctive differences in the shape of the response function response, i.e. the peaks of the response functions do not shift significantly with moderator thickness. Replacement of the PMMA slabs with high-Z material, such as lead or tungsten, should result in more energy-dependent structure in the responses.

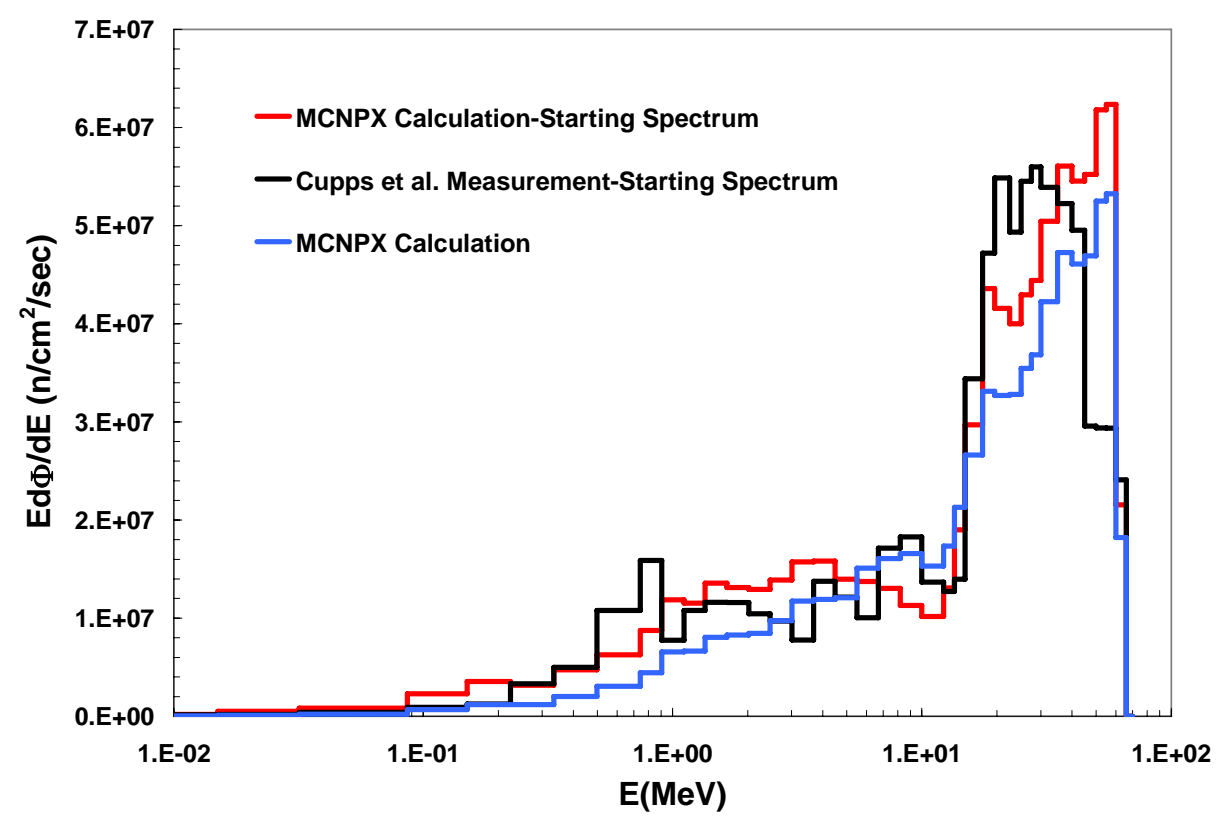

Fig.6 Neutron spectra at $190 \mathrm{~cm}$ isocenter for a $10 \times 10 \mathrm{~cm}^{2}$ field at Fermilab NTF.

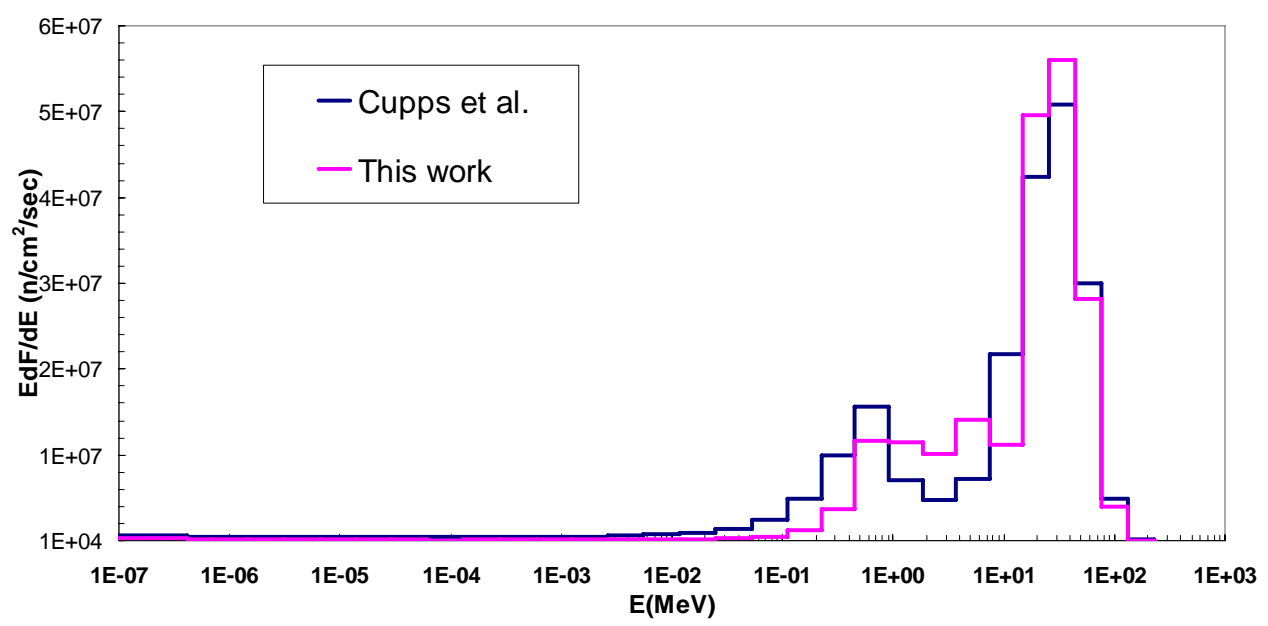

Fig.7 Comparison Of The Fermilab NTF Neutron Spectra Determined By Cupps et al. And This Work. 


\section{References}

[1] I. Rosenberg and M. Awschalom. Characterisation of a p(66)Be(49) neutron therapy beam I: Central axis depth dose and off-axis ratios. Med. Phys., 8:105-107,1981.

[2] V.R. CUPPS, A.J. Elwyn, A. J. Lennox, and T. Kroc, "Fermilab NTF Neutron Beam Energy Spectrum by Foil Activation," Proceedings of the 44th Annual Meeting of the Radiation Research Society, Chicago, April 14-17, p. 114, Radiation Research Society, (1996)

[3] M.A. Ross, P. M. Deluca Jr., D.T. L. Jones, A. Lennox and R. L. Maughan, Calculated Fluence Spectra At Neutron Therapy Facilities, Radiation Protection Dosimetry, v 70, n 1-4, 1997, p 481-4

[4] D. T. L. Jones, J. E. Symons, and T. J. Fulcher, Neutron Fluence and Kerma spectra of a p(66)Be(40) Clinical Source, Med. Phys. 19 (5), 1285, 1992.

[5] J. E. SWEEZY, "Development of a Boron Neutron Capture Enhanced Fast Neutron Therapy Beam," Ph. D. dissertation, Georgia Institute of Technology (2002).

[6] M. B. CHADWICK, P. G YOUNG, et. al., "Cross Section Evaluations to $150 \mathrm{MeV}$ for Accelerator-Driven Systems and Implementation in MCNPX', Nucl Science and Engineering, 131 3, 293 (1999).

[7] J. K. Tuli, Nuclear Wallet Cards, National Nuclear data Center, January, 2000.

[8] D.C. Kocher. Radioactive Decay Data Tables, A Handbook of Decay Data for Application to Radiation Dosimetry and Radiological Assessments. Oak Ridge, Tennessee. Oak Ridge National Laboratory Technical Information Center, U.S. Department of Energy. 1981.

[9] Zhonglu Wang, Bernd Kahn and John Valentine, "Efficiency calculation and coincidence summing correction of a germanium detector by Monte-Carlo simulation", 2001 IEEE Nuclear Science Symposium Conference Record (Cat. No.01CH37310), 2002, pt. 2, p 1037-41 vol.2

[10] M. REGINATTO, The "Few-Channel" Unfolding Programs in the UMG Package: $M X D_{-} F C 33, G R V \_F C 33$ and $I Q U \_F C 33$, UMG package, Version3.3-release 